\title{
Modes of Listening: Why, How and to What?
}

\begin{abstract}
This chapter presents a typology of the modes of listening employed across science, medicine, and engineering. It distinguishes between three purposes of listening and three ways of listening in the sciences. The three purposes discussed are diagnostic, monitory, and exploratory listening; the three ways are analytic, synthetic, and interactive listening. Using ample examples, this chapter illustrates the six modes of listening and the virtuoso mode-switching of scientists and other experts. It reflects on the incidence of specific combinations of purposes and ways of listening, and asks how these listening modes interact with the third dimension of listening: listening to what.
\end{abstract}

Keywords Diagnostic listening - Monitory listening - Exploratory listening - Analytic listening - Synthetic listening - Interactive listening

Most of this chapter has been published in open access as: Supper, A., \& Bijsterveld, K. (2015). Sounds Convincing: Modes of Listening and Sonic Skills in Knowledge Making. Interdisciplinary Science Reviews, 40(2), 124-144. Four of the six listening modes discussed below have been first introduced in Bijsterveld's 2009 grant proposal (see footnote 8 in Chapter 1), and in Pinch and Bijsterveld (2012: 14).

(C) The Author(s) 2019

K. Bijsterveld, Sonic Skills, https://doi.org/10.1057/978-1-137-59829-5_3 


\section{INTRODUCTION}

In 1917, the American composer and educator Sophie Gibling published an essay on "Types of Musical Listening." The kind of typology it presented held much sway with cultural commentators and musical critics in the early twentieth century: it distinguished between imperfect and ideal listeners. Among several types of imperfect listeners was the listener "who is no listener at all, who passively sits through a concert, intellectually contributing nothing; waiting, like a cabbage or a stone, for something to happen to him. He hears without listening" (Gibling 1917: 386). The ideal listener, in contrast, prepared himself for concerts emotionally and intellectually, listened past imperfections in specific performances to appreciate the beauty of the composition, and was ready to merge completely with the music, becoming a "purely abstract spirit" (p. 389). To Gibling, listening well was a matter of the "quality of a man's personality" (p. 388).

In the century following the publication of Gibling's essay in the Musical Quarterly, many more typologies of modes of listening have appeared, spanning fields as diverse as cultural studies, musicology, media studies, communication studies, and psychoacoustics. Like Gibling, some authors display strong preferences for particular modes, while others question the value of normative judgments (Stockfelt 1997; Subotnik 1991). Alongside those concerned with musical listening, authors have offered taxonomies of listening for domains such as radio broadcasting (Douglas 1999; Goodman 2010), film sound (Chion 2005/1990), and everyday environments (Truax 2001/1984).

Based on work published by Alexandra Supper and myself in 2015, this largely co-written chapter extends the discussion of taxonomies of listening to yet another set of empirical domains: science, medicine, and engineering. We developed a two-dimensional taxonomy of the listening practices in the sciences, one that takes into account both purposes of listening (the why) and ways of listening (the how). A particular strength of this taxonomy is that it allows us to show how practitioners shift between different modes of listening-an ability that is at least as important for knowledge making as is competence in using any one given mode of listening. Our aim is not to isolate listening from other skills, but to argue that our understanding of knowledge dynamics can be substantially deepened by attending to the ways in which listening modes inform the use of sonic skills in knowledge-making processes. 
As explained in Chapter 1, our use of the term mode does not imply an exclusive focus on the cognitivist dimension. We regard the modes of listening as being linked to particular bodily practices and embedded in a broader set of sonic skills. Sonic skills, in our approach, include both listening skills and the techniques that doctors, engineers, and scientists employ for making, recording, storing, and retrieving sound.

The goal of this chapter is thus to show how listening modes, and the ways in which they feed into sonic skills, cast light on processes of knowledge production in science, engineering, and medicine. We first explain the origins of our typology of listening modes, which has drawn inspiration both from existing scholarly work in sound studies and from actors' categories. We then outline our typology in more detail. In the final two sections, we outline how an analysis of listening modes can usefully be integrated into a study of broader sonic skills, and substantiate the relevance of both notions - listening modes and sonic skills-for understanding processes of knowledge production.

\section{Existing Taxonomies of Listening: Analytic And Actors' Categories}

Thinking about listening modes has a long tradition both in the academic field of sound studies and among practitioners who work with sound. Perhaps the best-known typology of modes of listeningalthough it may be more accurately characterized as a typology of listeners - is the one developed by Theodor Adorno (1977/1962), which distinguishes between figures such as experts, good listeners, culture consumers, emotional listeners, and entertainment listeners. Adorno makes no secret of his preference for structural listening, a mode commonly displayed by experts, nor of his contempt for practices such as entertainment listening. In this preference, Adorno's typology echoes the concerns of many music theorists and critics since the middle of the nineteenth century, beginning with the Viennese music critic Eduard Hanslick, who offered an opinionated taxonomy to distinguish "poor listening practices from the true method of listening, aesthetic listening" (Hui 2013: 34). Similar taxonomies accumulated in the course of the nineteenth and early twentieth century, usually taking attentive, absorbed listening as their gold standard. ${ }^{1}$ Anxieties about proper listening modes were not limited to the world of classical music; they also took hold in the domain of radio broadcasting. Historians of broadcasting have traced 
public debates about proper modes of radio listening back to the 1930s, when many commentators warned of the social, political, and psychological dangers of distracted listening (Goodman 2010) and tried to persuade "the listener to 'incline their ear' not only in the right direction (towards beautiful, honest and reputable things), but also in the right way (selectively, attentively and with appropriate discrimination)" (Lacey 2013: 183).

In the course of the twentieth century these typologies, with their outspoken normative preferences, increasingly came under fire or were put into historical perspective. Fervent critiques of Adorno's categorization scheme and his advocacy for structural listening were expressed within musicology (Subotnik 1991, 1996; Stockfelt 1997), and inspired an abundance of work proposing relativist and postmodern alternatives (Dell'Antonio 2004). Music theorist Ola Stockfelt (1997), for instance, argued that different modes of listening are appropriate for and indeed demanded by different genres-Adorno's preferred mode, structural listening, being adequate only for a very specific type of Western art music. Modes of listening should therefore be judged in terms of adequacy to a genre: adopting an adequate mode means being able "to listen for what is relevant to the genre" (Stockfelt 1997: 137). With this assertion, Stockfelt moves away from treating modes of listening as personal characteristics (linked to particular character traits or socioeconomic factors), and instead treats them as part of a repertoire from which individuals can choose. Moving between different modes is not only possible, but common.

This possibility of shifting between modes of listening (often akin to shifting between levels of attention) has been an important element of many recent typologies. For instance, in his book Acoustic Communication, Barry Truax (2001/1984) distinguishes three modes of listening, each characterized by a different level of attention. The first kind, background listening, is entirely passive, listening that is not directed at achieving any practical purpose. By comparison, listening-in-readiness (such as the practice of recognizing a vehicle by its sound) is more active, while listening-in-search (as exemplified by a ship captain whistling and using the echo for orientation) is more active still. Truax's research is embedded in a normative concern about noise pollution in modern society, as he worries that the skills of listening-in-readiness and listening-in-search are rapidly dwindling due to the noise of modern technology. 
In her book Listening In, historian of technology Susan J. Douglas (1999) offers an "archaeology of radio listening" that goes well beyond a distinction between concentrated and distracted listening practices. Among the many listening modes she mentions are linguistic, musical, informational, exploratory, story, advertisement, and fidelity listening (1999: 33-35). Some of Douglas's categories describe listening in terms of what someone is listening to (stories or ads, for example), some in terms of what they listen for (such as information or sound quality), and some in terms of how they listen cognitively. Examples of these cognitive ways of listening are dimensional listening, in which the listener imagines spaces, and associational listening, in which networks of memories are triggered through sound.

In this chapter, we follow in Douglas's footsteps to develop a typology that operates on more than one dimension, but we do so in a way that explicitly asks how these dimensions relate to each other. Like Douglas and other scholars, we start from the idea that listeners have a repertoire of listening modes available between which they can shift. We go one step further, arguing not only that shifting between different modes of listening is possible and common, but that the capability of shifting is itself an essential skill in the knowledge-making practices of many scientists, engineers, and doctors.

Before delving into our own typology of listening modes in the sciences, we should briefly acknowledge that it was inspired not only by scholarly work in sound studies, but also by the discourses of the actors that we studied. That is to say, some of our categories are based on actors' categories. For instance, the distinction between "monitory listening" (listening to monitor whether everything is working well) and "diagnostic listening" (listening to diagnose the specific source or cause of a problem), which we will explore in more detail in the next section, is present in the discourse of car mechanics themselves. It played an important role in the formalization and professionalization of the trade of German car mechanics during the 1930s, as discussed by Stefan Krebs $(2012 \mathrm{a}, \mathrm{b}, \mathrm{c})$ and in this essay's previous chapter. To convince car drivers to entrust their faulty cars to the new profession of certified car mechanics, the mechanics needed to ensure that car drivers would trust their own ears enough to know when to bring their car to the garage, but not enough to try to fix it themselves. Once it was established that there was a problem, the task of diagnosing and fixing that problem would be left to the mechanics. In their effort to gain exclusive jurisdiction over 
the ability to repair cars, the mechanics demarcated their skill of professional diagnostic listening from the monitory listening skills of drivers. The distinction between two listening modes, in other words, helped the mechanics in their quest for cultural authority.

Explicit references to taxonomies of listening modes are even more widespread in the scientific community dedicated to sonification research, which aims to systematically explore the use of sound to represent data and convey information. Indeed, the distinction between different modes of listening has been a stable feature of the sonification literature, from some of the founding texts of the community (Gaver 1989; Williams 1994) to much more recent contributions (Vickers 2012; Grond and Hermann 2014). An example is William Gaver's (1989) work on the SonicFinder, an early attempt to use auditory displays as part of a computer interface, which was a forerunner of now-ubiquitous sounds such as those announcing new emails or accompanying the moving of a file into a digital trashcan. The SonicFinder builds upon a fundamental distinction between two modes of listening: everyday listening and musical listening. The former is directed at identifying the sources of a sound, the latter at its formal characteristics, such as pitch or timbre. Gaver's displays are designed to exploit everyday listening in particular: "If sounds are to be used in the interface, they should be used much as they are in our everyday lives .... We do not hear the pitch of closing doors; instead we are more likely to hear their size, the materials from which they are made, and the force used to shut them" (Gaver 1989: 72ff). This distinction still resonates in sonification research today, and-although many sonifications do demand a certain degree of musical listening skill, as pitch is a widely used parameter in sonification designs - so does the emphasis on everyday listening skills (Hermann 2011). The sonification community struggles with the fact that many potential end users of sonification (specialists in the scientific domains from which data are translated into sound) are reluctant to use sonification because they distrust their own ears. ${ }^{2}$ In that situation, references to everyday listening can reduce the fear of listening, and thus potentially help to convince people of the benefits of sonification.

Similarly, scholars in the sonification community frequently make a distinction between synthetic listening (listening to sounds holistically) and analytic listening (focusing on specific elements of the sound), which has been appropriated from literature in auditory perception research (Hermann 2002; Worrall 2009; Walker and Nees 2011; Williams 1994). 
This distinction also turned out to be useful for our own typology, which adopts the categories of analytic and synthetic listening-along with an additional category of interactive listening - as two fundamentally different ways of listening.

Our typology thus makes use of existing categories employed by the actors that we study, but only as a partial inspiration, in tandem with secondary literature. ${ }^{3}$ The most important contribution of our typology above and beyond the existing actors' categories is that it addresses different modes of listening in two dimensions, and places them in a broader context of the sonic skills that are involved in knowledge production.

\section{Purposes of Listening: Why Scientists, Engineers, AND Physicians Listen}

Our proposed typology takes into account both the purposes for which scientists, engineers, and physicians listen and the ways in which they do so. In this section, we set out three purposes of listening-monitory, diagnostic, and exploratory-before adding three different ways of listening - synthetic, analytic, and interactive- to arrive at nine possible combinations of modes.

Monitory listening refers to checking for possible malfunctions-for instance, when car drivers pay attention to "the rhythmic and silent run of the engine" and "the regular humming of the gearbox or chain drive" (Küster 1919, cited in Bijsterveld and Krebs 2013: 20). Monitory listening is also employed in the scientific laboratory and field by researchers checking the proper running of their equipment (Bruyninckx 2013; Mody 2005), and in the hospital by doctors and nurses monitoring the vital signs of patients. Monitory listening usually accompanies other tasks and activities, often unrelated to sound-whether driving a car, operating a microscope, or performing surgery on a patient. The fact that the sound can be perceived in the background while focusing on other tasks, but that sudden and unexpected changes in the sound nonetheless immediately draw the listener's attention, is of great benefit here. Similarly, the ability to "monitor multiple processes simultaneously" (Dayé and de Campo 2006: 350) has been considered an advantage of sonification over graphic displays. Consequently, sonifications developed specifically for monitoring have been an important area of sonification research in recent years, ranging from applications developed for the 
medical field to those monitoring web server activity. It has even been claimed that the monitoring of information in the background while users attend to another task is where sonification and auditory display really "come into their own" (Vickers 2011: 456).

Whereas monitory listening is concerned with establishing whether something is wrong, diagnostic listening is about pinpointing what precisely is wrong. The quintessential example of diagnostic listening is that of physicians using their stethoscope during physical examinations to distinguish the "normal" sounds of a healthy body from the "abnormal" sounds of a sick one and to diagnose specific diseases based on those sounds. This skill is not limited to the medical field. In fact, practitioners from other domains frequently reference the listening practices of doctors to explain their own: "If the physician cannot make his diagnosis by the appearance of the patient, he will take his stethoscope and listen to the patient's body. This is how you ought to proceed with the car engine as well," proposed one car mechanics handbook (Hessler 1926, cited in Krebs 2012c: 83). When physicist Cornelis Zwikker (1934) discussed sixteen car sounds and their causes, he described "knocking" as a symptom of an "advanced-stage disease" (p. 75). As Stefan Krebs and Melissa Van Drie (2014) have shown in their comparative work on doctors and mechanics, such use of medical metaphors and pictures staging mechanics as "car doctors" became widespread from the 1920s onward. As we have seen, medical techniques such as differential diagnosis became models for automotive engineering, just as the trust invested in the medical profession became a model for the role of the car mechanic (pp. 95-97). In ornithology, the skill of diagnostic listening was, and still is, considered essential for the correct identification of species, but also for ensuring adequate recording quality-examples will follow in Chapter 4. And in sonification, diagnostic listening plays an important role in quality control, as errors in sonification design are often picked up by listening.

Exploratory listening, thirdly, refers to listening out for new phenomena. The notion was developed by Douglas (1999) for the practice of radio hams trying to discover distant stations, but it also plays a part in the listening practices of scientists. Narratives of field observation in ornithology, for instance, often feature ornithologists letting themselves be guided through the woods by ear, always listening out for rare, exotic, or appealing bird songs, such as in this account by the naturalist J. Schafer:

While going through a thicket of hazel brush, briars and vines, a bird was heard singing so softly that it was some time before I could locate the 
exact place where the song came from. After listening a short time I recognized the song to be that of a Catbird, but to make sure of the identity of the singer, it was driven from its hiding place. (Schafer 1916, cited in Bruyninckx 2013: 36)

Although sonification is usually a more mundane activity, taking place with headphones in front of a computer screen, the exploratory listening of sonification researchers, too, can become entangled with romantic narratives of adventurous scientists making chance discoveries thanks to their dedicated attention to their sonic environment-as in this description of Robert Alexander's solar wind sonifications:

Alexander typically compresses 44,100 data points into a second of sound, the sampling rate of a compact disc.

Then, he puts on his headphones.

On that particular day he found a hum everywhere in the data. "I thought I was hearing noise," he recalls.

But it was more than that. The hum had a frequency of 137.5 hertz which would correspond to about 26 days in the original data. That would be the time taken for a particular feature on the sun to swing back around. In other words, he could lock on a feature and listen in.

Alexander realized what he was hearing and messaged a colleague. "The frequency I'm listening to is the rotation speed of the sun. I don't think anyone's ever done this."

In a recent video documentary for Vice Magazine, Alexander explains the exploratory nature of his listening: "I was digging through, you know, 20 or 30 different data parameters and listening to them all, and I realized that if I listened to carbon, that I could hear a very strong harmonic presence." 5 In the astrophysical research group he was working with, carbon had not previously been mentioned as relevant to the study of solar wind; instead, different types of solar wind had been distinguished by measuring oxygen charge states. It was through listening to different sonic realizations of the same dataset that Alexander's research group became aware of the potential of carbon as a more reliable indicator for solar wind activity. The results were written up and published in the Astrophysical Journalwith a brief mention of the sonification process that had led to the discovery, but none of the romantic flourishes of a lone researcher making a chance discovery when donning his headphones (Landi et al. 2012). 


\section{Ways of Listening: How Scientists, Engineers, and Physicians Listen}

The three modes of listening discussed so far were concerned with the purposes for which scientists, engineers and physicians listen; in the following, we introduce three modes that describe the ways in which they do so: synthetically, analytically, or interactively. These three modes do not exclude the purpose-related modes; rather, any given listening practice of a scientist, engineer, or physician can always be characterized both in terms of its purpose and in terms of its manner. A car driver listening to the roar of the engine while driving, for instance, engages in both monitory and synthetic listening.

The term synthetic listening comes from literature in auditory perception research, and has become a mainstay of sonification literature. Its meaning is usually defined in opposition to another category in our typology, analytic listening. For instance, in the first book publication on sonification, the terms were defined as follows:

Synthetic perception takes place when the information presented is interpreted as generally as possible; for example, hearing a room full of voices or listening to the overall effect of a piece of music. Analytic perception takes place when the information is used to identify the components of the scene to finer levels; for instance, listening to a particular utterance in the crowded room or tracking one instrument in an orchestral piece or identifying the components of a particular musical chord. (Williams 1994: 98)

This definition of synthetic listening and analytic listening is also applied in Albert Bregman's (1994) influential work on auditory perception, and still resonates in sonification discourse today (Hermann 2002; Worrall 2009; Walker and Nees 2011). For sonification, both synthetic and analytic listening play a role-both the ability to perceive complex auditory events as a whole, and the ability to break the whole down into its component pieces and single out particular streams of sound for attention. In addition, the capacity to switch between these different modes is considered an important asset for the use of sonifications. The experience of attending a concert is often used as an example both of how people can perceive a piece of music as a whole and of how they analytically attend to specific instruments: "in a concert hall we can hear a symphony orchestra as a whole. We can also tune in our focus and attend to 
individual musical instruments or even the couple who is whispering in the next row" (Hermann et al. 2011: 3).

When medical students learn to use their stethoscopes, they are first learning the skills of analytic listening: navigating an initially confusing world of sound by differentiating the sounds of the patients' bodies from the sound produced by the tool itself and the sound of their own body. However, the skill of synthetic listening is equally important for the practices of scientists, engineers, and mechanics. Recall the 1965 article for apprentices in mechanics cited in the previous chapter, which claimed that diagnosis only starts when one complex sound is disaggregated into many single sounds. Frequently, successful use of sonic skills involves the combination of analytic and synthetic listening at different stages of the process of knowledge production. The quick identification of a bird in the field, for example, often involves synthetic listening, as ornithologists listen for general features and recognize the bird "more by the quality or style, or both, of its utterance than by the number and succession of its notes" (Summers 1916: 79). Once that quick identification has been made, the ornithologist may listen analytically to rule out confusion with similar-sounding species, or to notate specific elements of the sound.

Although synthetic and analytic listening are usually defined as opposites, they have one important aspect in common: both modes assume that the sound source itself is stable or unfolds according to its own dynamic rules. In many instances where scientists, engineers, and physicians listen, however, they actually intervene into the sounds while listening. We therefore distinguish an additional way of listening, that of interactive listening. If synthetic listening means hearing the whole orchestra and analytic listening means focusing on a particular stream of sound (perhaps the second oboe), interactive listening means that the listener decides to replace the second oboe with a didgeridoo halfway through in order to better grasp the dynamics of the piece. Scientists, physicians, and engineers often engage in such interactive listening in order to find out more about their subjects. Ornithologists may interact with the birds that they study by deliberately exposing them to specific sounds-such as recordings of birdsongs or traffic noise-in order to elicit a response (Bruyninckx 2013: 94ff). Car mechanics, too, often engage in interactive listening, for instance when listening for changes in the sound of the engine while changing gears; and so do car drivers, when they pay attention to the sounds of the car in deciding when to 
shift gears. Interactive listening to car engines can thus serve both monitory purposes (for drivers) and diagnostic purposes (for mechanics).

Interactive listening is also common in sonification research, where it is used mainly for diagnostic or exploratory purposes. ${ }^{6}$ As our ethnographic research has shown, diagnostic interactive listening is especially common during the design process: errors in the sonification design (or even in the underlying dataset) often express themselves as discrepancies between expected and actual sounds, and can be corrected by alternately adjusting settings and listening to the results until the expectations and the outcome are aligned. Exploratory interactive listening has also become increasingly popular in sonification research, a trend attested by the growth of a whole subfield dedicated to "interactive sonification" (Hermann and Hunt 2005, 2011). In interactive sonifications, users can "change selections quickly and easily to gain multiple auditory viewpoints" (Flowers 2005: 4), which are intended to give a better understanding of the data, especially for exploratory tasks.

At first glance, the categories of synthetic, analytic, and interactive listening may seem similar to Barry Truax's (2001/1984) distinction between background listening, listening-in-readiness, and listening-in-search. Truax's example of listening-in-search, in which a ship captain whistles and uses the resulting echo for navigation, could be considered an instance of interactive listening. However, in Truax's classification, the three modes are distinguished by the different degrees of active attention paid by the listener, whereas in our scheme it is a matter not of different degrees, but of different kinds of attention. And although the categories of synthetic and analytic listening emerged from psychoacoustic research, our approach does not assume that these listening skills are limited to the mind only. Rather, they are enmeshed with particular bodily strategies-examples might be a doctor percussing a patient's chest, an ornithologist cupping his hands around his ears and "rotating slowly like an aural CCTV camera" (Lorimer 2008: 391) while listening out for a particular bird, or a sonification researcher convulsing in pain when enduring unpredictable and piercing sounds in the attempt to identify errors in the sound-generating computer code.

Distinguishing modes of listening on two dimensions can give us a multilayered and nuanced appreciation of the listening practices involved in scientific research, medical work, and engineering. Looking at only one dimension in isolation would give us a very partial understanding of these practices. For instance, if we ask only why scientists, engineers, 
Table 3.1 Overview of listening modes

\begin{tabular}{|c|c|c|c|}
\hline Why & Synthetic listening & Analytic listening & $\begin{array}{l}\text { Interactive } \\
\text { listening }\end{array}$ \\
\hline Monitory listening & $\begin{array}{l}\text { Attending to } \\
\text { overall features of } \\
\text { sound for the pur- } \\
\text { pose of monitoring }\end{array}$ & $\begin{array}{l}\text { Attending to } \\
\text { specific character- } \\
\text { istics of sound for } \\
\text { the purposes of } \\
\text { monitoring }\end{array}$ & $\begin{array}{l}\text { Interacting with a } \\
\text { sound source for } \\
\text { the purposes of } \\
\text { monitoring }\end{array}$ \\
\hline Diagnostic listening & $\begin{array}{l}\text { Using a (quick) } \\
\text { overall impression } \\
\text { of a sound for } \\
\text { the purposes of } \\
\text { diagnosis }\end{array}$ & $\begin{array}{l}\text { Attending to } \\
\text { specific character- } \\
\text { istics of a sound } \\
\text { for the purposes of } \\
\text { diagnosis }\end{array}$ & $\begin{array}{l}\text { Interacting with a } \\
\text { sound source for } \\
\text { the purposes of } \\
\text { diagnosis }\end{array}$ \\
\hline Exploratory listening & $\begin{array}{l}\text { Listening out for } \\
\text { general impressions } \\
\text { for the purposes of } \\
\text { exploration }\end{array}$ & $\begin{array}{l}\text { Attending to } \\
\text { specific features } \\
\text { of sound for } \\
\text { the purposes of } \\
\text { exploration }\end{array}$ & $\begin{array}{l}\text { Interacting with } \\
\text { the sources of } \\
\text { a sound for the } \\
\text { purposes of } \\
\text { exploration }\end{array}$ \\
\hline
\end{tabular}

and physicians listen, we may miss the particular bodily and cognitive skills that their listening entails. Likewise, there is not one single technique for monitory listening-listening for the purposes of monitoring may involve either focusing on general patterns of sound (as car drivers do when listening out for the auditory feedback of their car engines and surroundings) or focusing on particular elements of that sound (as physicians do on their daily ward round when checking whether a symptom discovered during yesterday's diagnosis has cleared up), or even interacting with the source of that sound (as ornithologists do when playing a sound recording to a bird to elicit a reaction). On the other hand, addressing the dimension of how we listen in isolation, without taking into account the purposes, risks losing sight of why those sonic skills matter in the first place. The listening modes could then be taken as ends in themselves, rather than as analytical tools telling us something about how scientists, engineers, and physicians use their bodies and senses for particular ends that in and of themselves may not have anything to do with sound.

Our graphic representation of all possible combinations of purposes and ways of listening (Table 3.1) is not, however, intended to suggest that all the listening modes mentioned are equally predominant in the 
sciences. We noted above that listening practices in the sciences can always be described in terms of both purposes and ways of listening. We have also given empirical examples of all the potential combinations of purposes and ways of listening as listed in the cells of Table 3.1. Our cases studies have thus demonstrated the existence of all these optionsbut that does not mean all modes or all possible combinations have the same incidence in the knowledge practices of scientists, engineers, and physicians.

We have come across numerous examples of analytic listening for the purpose of diagnosis, and synthetic listening for the purpose of monitoring, but our case studies offered only a few illustrations of interactive listening for the purpose of monitoring. Apart from ornithologists playing recorded bird sound to make birds respond and betray their presence at a particular field site, we have only one other example. In intensive care units, all kinds of machines help the medical staff to monitor the physical condition of patients. These instruments' alarms, Anna Harris has explained, can be tweaked manually, meaning that the staff can define the parameters that will set off the alarms. Nursing students are told "to set their alarms 'wide,' so that they are alerted to even the slightest deviance in heart rate or blood pressure." Experienced nurses, in contrast, may tighten the alarms to reduce the number of alerts, "as they have the expertise which enables them to monitor a patient without the continual sounding of alarms" (2015: n.p.).

\section{Sonic Skills: Virtuosity in Shifting Modes and Handling ToOls}

Although Table 3.1 might initially give an impression of stagnancy and rigidity, its strength lies in providing a stable reference point for the dynamic listening practices that we found. The professional status of some practitioners - such as doctors or car mechanics-is intimately connected with their recognition as expert diagnostic listeners. Yet, we argue in this section, it is often the ability to shift between different modes of listening, rather than specialization in one particular mode, that expresses the virtuosity of their sonic skills and helps them to underpin their knowledge claims. Furthermore, this ability to shift is closely linked to the handling of tools and to broader sonic skills that go beyond the modes of listening themselves. 
In the everyday knowledge practices of the experts we studied, the different listening modes often build upon each other. For instance, it is important for the successful work of car mechanics-for which diagnostic listening is essential-that car drivers recognize the need to bring their car to the garage, for which monitory listening is crucial. In some instances, a shift in the purpose of listening goes hand in hand with a shift in the way of listening. The solar wind sonifications described above were, at least at first, an example of synthetic exploratory listening, as Robert Alexander somewhat randomly listened for general patterns in the data in the hope that something of interest would jump out at him. Once he noticed harmonic presences in the charge states of carbon, however, a shift seems to have occurred towards listening to a particular element in order to diagnose the dynamics of solar wind activity. That involved focusing his attention on one specific aspect of the sound. In other words, there was a shift not only in the purpose of listening (from exploratory to diagnostic), but also in the way of listening (from synthetic to analytic).

In the last two examples, diagnostic listening followed monitory or exploratory listening, while analytic listening followed synthetic listening. It might be tempting to conclude that the modes of listening occur in a fixed order, with diagnostic and analytic listening as the natural culmination and end-point. This is not the case, however. An instance from ethnographic research in the hospital is one illustration that monitory listening does not always precede diagnostic listening. During the initial examination after a patient is admitted to hospital, doctors usually engage in diagnostic listening. But when performing subsequent checkups during their daily rounds, they are more likely to perform monitory listening, checking whether specific symptoms detected during earlier diagnoses persist or have improved.

In fact, the different modes often occur in constant back-and-forth shifts, with the listener repeatedly zooming in and out. Many sonification designs - especially those made for the purposes of data explorationare deliberately built to facilitate rapid shifts between different modes of attention. In Thomas Hermann's (2002) dissertation on sonifications for exploratory data analysis, for instance, the listener is described as being engaged in different modes of listening, and many of the proposed sonification designs feature multiple streams of data that can be listened to simultaneously or separately. They seem to be designed for a listener who 
may at times synthetically listen to several streams of sound simultaneously, and at other times analytically hone in on particularly promising specific sound streams. That listening is interpolated, of course, with the occasional intervention into the sound source itself. Constantly switching between analytic, synthetic, and interactive modes of listening is thus facilitated and intended by the sonification design.

This example flags up the connection between the ability to shift between modes of listening and the availability of particular tools. The introduction of a novel type of stethoscope in German automotive engineering during the interwar period would be another, earlier example of how tools can effectively enable the process of mode-shifting. Whereas listening rods and traditional stethoscopes had been used to listen to one component of the car engine, the new stethoscope had two sensors. These sensors, the Tektoskop and the Tektophon, enabled mechanics to listen to two differently located components of the engine simultaneously and make a detailed comparison of the sounds they heard (Anonymous 1929b, cited in Bijsterveld et al. 2014: 80). Such a construction afforded shifts between synthetic and analytic listening, as it brought together distinct sounds in one listening "frame" while keeping alive the option of alternation in auditory focus.

Similarly important for the skill of mode-shifting was the rise of sound recording technologies in ornithology. The phonograph, sound camera, gramophone, and tape recorder enabled ornithologists to record the sounds of birds in ways that many considered more accurate, less dependent on individual listening capacities, and therefore more "objective" than the notation of sound in traditional onomatopoeic terms, musical staff, or graphic systems (Bruyninckx 2013: 63). In addition, these tools made it possible for ornithologists to repeat their listening exercises as often as they wanted, or even to slow down the recording, thus improving precision in notation after the field trip (Bruyninckx 2013: 49). This enabled cycles of analytic listening, with repeated listening allowing ornithologists to focus on different components of bird sound across different listening sessions.

Slowing down gramophone playback was useful not just for those ornithologists who notated bird sound manually, but also for those who favored automated visualizations. For instance, the British ethologist and ornithologist William Homan Thorpe, a strong advocate of the spectrograph (to recall: an instrument that visualizes the frequency and intensity of sound over time), acknowledged that the analysis of sound 
spectrograms was best accompanied by listening to the sound recordings and, in particular, by doing so at reduced speed. According to Thorpe, slowing down gramophones from 78 to 28 cycles made the complexities and varieties of bird sound-such as high frequencies and rapid sequences-more easily accessible to the human listener and enabled a focus on different components of the sound than those that prevailed at 78 cycles. Thorpe cautioned, however, that recordings played back at reduced speed would "at first hearing have no apparent resemblance to the original" (Thorpe 1958: 542). Despite the analytic value of listening at reduced speed, synthetic listening was often best accomplished at the original speed. An important function of the "infinitely variable speed turntable" favored by Thorpe (1958: 542) was precisely that it enabled scientists to quickly and easily switch not just between different speeds of playback, but also between different modes of listening. The availability and use of particular recording and playback tools thus affected the options for modes of listening, and therefore the character of mode-shifting, which in turn fed into the knowledge claims that were formulated.

Tools can open up particular modes of listening and particular means of shifting between modes, but they may also enhance the epistemological status of listening practices in science, medicine, and engineering. As Tom Rice $(2008,2010)$ and Melissa Van Drie (2013) have shown, the stethoscope is an important signifier, a visual icon, of the doctor's expertise and jurisdiction. Even though the practical importance of auscultation for medical diagnosis has declined over the years, the stethoscope has retained its symbolic function. Indeed, its symbolic sway reaches beyond the confines of the medical field, as other professional groups have also appealed to the stethoscope's symbolic authority. In the automotive industry, for instance, engineers and mechanics have often been portrayed in white coats and using a stethoscope on a car engineexplicitly alluding to the image of a doctor using a stethoscope to examine a patient (Krebs and Van Drie 2014). Tools may thus function as symbolic capital underlining the epistemological authority of their users.

It is important to note, once again, that the sonic skills involved in knowledge-making practices are not a matter of listening alone. The examples of ornithology and sonification offered in this chapter have already hinted that the recording and design of sounds are equally important elements of sonic skills. So are the ability to reproduce sounds through physical mimicry (Harris and Van Drie 2015) and to store, retrieve, and circulate sound recordings (Bruyninckx 2013). 
These elements, too, can enhance or reduce epistemological authority. To take the case of sonification, many sonification researchers regard the fact that "the traditional carrier of the symbolic knowledge generated by science, paper, hardly begins to meet the requirements of communicating sound" (Dayé and Campo 2006: 360) as a major stumbling block for the scientific acceptance of their techniques. Sound has traditionally been difficult to circulate and integrate with written text, but the development of digital media permitting an easier integration of text and sounds may help sound recordings to catch up, at least partially, with graphical images when it comes to exerting scientific authority (see Supper 2012, 2015). Here, too, tools and sonic skills are closely intertwined.

\section{The Missing Third Dimension: Listening to What?}

So far, we have proposed a two-dimensional typology of listening modes, and offered some reflections on how these listening modes-in particular, the ability to shift between different modes of listening-link up with other sonic skills in knowledge-making practices. However, a third dimension of listening has mostly been taken for granted in our analysis: the dimension of what it is that scientists, engineers and physicians are listening to. Sidestepping this dimension in our typology was a deliberate decision. Whereas the other two dimensions allowed us to configure a finite number of categories that can nonetheless exhaustively describe the listening practices of scientists, engineers, and physicians, the question of what they are actually listening to opens up an infinite number of possible answers. It defies categorization. That does not, of course, mean that the subject matter to which listeners lend their ear is irrelevant.

On the contrary, it matters a great deal what scientists and other practitioners listen to, and it would be a grave mistake to disregard subject matter when discussing listening modes and sonic skills. STS scholar Sophia Roosth has noted that "[s]ound has been used in science to explore and gain direct experience of inaccessible places: to sound the depth of an ocean, the inside of a body, and the furthest reaches of space" (Roosth 2009: 349). We would add that this "direct experience" is often highly mediated by scientific instruments and sonic skills, both of which affect the scientists' very conceptualization of what they are studying. An example from ornithology will help us to show that subject matter and sonic skills are inextricable. The sonic skills involved in listening 
to, recording, storing, and retrieving sound, we claim, co-define the conception of the objects under study.

In the 1930s, British and American ornithologists struggled immensely with the technical and logistical complexities of making sound recordings of birds in the field. While Cornell University student Albert Brand and his colleagues used a large, sensitive sound camera and testing equipment to capture bird sound, amateur birdwatcher Ludwig Koch and his British companions-ornithologists and recording engineers working for the $\mathrm{BBC}$ - used a phonograph recorder and wax disks. What they had in common was the need to move heavily loaded vans around in order to do their recording work. Not only did this affect where they could make recordings (the site had to be accessible by road, for instance); it also influenced what they recorded. Although the sounds of nature were their primary interest, their microphones also picked up the sounds of modern civilization-as they often discovered, to their dismay, after the fact (Bruyninckx 2013: 64ff).

The two groups came up with their own technical solutions to these challenges, and each solution had its consequences. Choices regarding the type and positioning of microphones, for instance, had not only implications for how they made their recordings, but also for their conceptions of birdsong and for their research findings. The British group carefully installed sets of microphones around the space in which a particular bird was expected to produce its song, and would adjust the sound level of each microphone retrospectively, in the editing process. With a little luck, this resulted in recordings that captured both the bird's song and its environmental sounds, giving the recording an atmospheric touch even though the song was foregrounded. If the bird flew away, however, the whole set-up had to be recreated (Bruyninckx 2013: 71ff).

Whereas the British group worked on BBC nature films that were meant to educate and entertain a wide audience, the ornithologists at Cornell were interested first and foremost in establishing a firm scientific reputation. This may partially explain why they adopted a different approach to recording, making use of a parabolic reflector surrounding a microphone. The surface of the parabola reflected sound waves to a dynamic microphone at its focal point. Focusing the sound waves in this way dramatically increased the input to the recording equipment and concentrated it to at least twenty decibels louder than the sounds not caught by its narrow shape, which amounted to an amplification of about fifteen times (Sellar 1976, cited in Bruyninckx 2013: 73). 
The reflector enabled the Cornell ornithologists to pick up bird sound from a considerable distance, making the exact position of the microphones less important and bringing less accessible parts of nature within easier reach. At the same time, microphones with parabolic reflectors staged a "sterile sound," creating a "close-up" of acoustic events. This, argues Bruyninckx, produced not only a form of sound that was halfway between the laboratory and the field, but also "a still-life motif in a clearly demarcated acoustic landscape" (Bruyninckx 2013: 55, 76, 79).

It was only at the beginning of the twenty-first century that ornithologists began to realize their focus on bird sound proper had come at a price. Recent research has indicated that at least one bird species sings at a higher frequency when living in urban areas than the same species living in rural surroundings (Bruyninckx 2013: 151; Slabbekoorn and Peet 2003). For a long time, ornithologists had simply missed this possibility as a consequence of their preference for clean sound. They had treated environmental noise as a disturbance rather than as an informant. Their approach had been both enabled and constrained by their tools, and their carefully crafted sonic skills had affected their knowledge claims.

\section{Conclusions}

This chapter has argued that we need both the notion of listening modes and the notion of sonic skills to understand how sound has been used as a path to knowledge making in science, medicine, and engineering. Its analysis began with a typology of listening practices. Certainly, our project is not the first to present such a typology; typologies of listening abound in scholarly work on sound. Building on such literature and on our own case studies of Western scientists, doctors, mechanics, and engineers, we have distinguished between six modes of listening, operating on two dimensions. Monitory, diagnostic, and exploratory listening refer to different purposes of listening in the sciences; analytic, synthetic, and interactive listening express particular ways of listening. We have also stressed, however, that scientists, engineers, and doctors are not required only to engage in any given one of these modes, but additionally-or especially-to shift between modes. Tools and instruments, whether multichannel stethoscopes, tape recorders, all sonification software, enable particular forms of listening and mode-shifting.

We also pointed out that sonic skills are not limited to listening skills. Although our notion of sonic skills encompasses the skills that experts 
need in order to employ the various listening modes, it also encompasses the ability to design, record, store, mimic, and retrieve sound. All these sonic skills are associated with the handling of specific instruments-virtuosity in sonic skills means not just the ability to use one's ears, but also the ability to handle various tools and instruments. These practical tools often also play a symbolic role in the knowledge practices of scientists, engineers, and doctors: they can symbolically enhance the epistemological status of listening.

Sonic skills have repercussions on the knowledge claims that can be made in science, engineering, and medicine. The decision to employ a particular technique in the recording of sound, for instance, is not an innocent one: it can affect the substance of knowledge claims that are made and the conceptions of the objects under study. In order to understand the knowledge practices of scientists, engineers, and physicians, then, it pays to consider the listening modes and sonic skills involved in their production. Doing so deepens our insights in the role of sound and listening in the sciences, and might also inspire research into the contribution of other non-visual senses in knowledge making.

As for sound and listening, there is more to discover than we have done so far. We are interested, for instance, in the reopening of debates on the status of sensory information every time new, and epistemologically still unstable, tools are introduced that make the inaudible audible or translate data from one sensory mode into another, as was the case for the spectrograph. We still have much to learn about the conditions under which sonic skills are accepted or contested in knowledge-making practices. These are the topics of the following chapters. But without an understanding of modes of listening, and of their relationship with tools and the skills to handle them, we cannot begin to tackle those issues.

\section{Notes}

1. The sudden increase of interest in listening practices in the late nineteenth and early twentieth century has been linked to anxieties related to the rapidly changing world of music, which had been shaken up by new tuning systems, new tones, and new music theories (Hui 2013), as well as the introduction of new sound technologies such as the gramophone (Maisonneuve 2001).

2. Personal interviews by Alexandra Supper with Christian Dayé (March 17th, 2008) and Alberto de Campo (October 16, 2009). 
3. In some cases, it can be difficult to ascertain where the primary literature ends and the secondary literature begins. This is especially true for sonification, as sonification researchers frequently refer to literature by film scholars such as Michel Chion or composers such as Pierre Schaeffer when publishing in sound studies or musicology journals (Vickers 2012; Grond and Hermann 2014).

4. Markendaya, Virat. (2012). Listening to the Sun on a Loop: a Composer Pricks his Ears up for NASA and Helps to Make a Discovery, Scienceline, available at http://scienceline.org/2012/03/listening-to-the-sun-on-aloop (last accessed August 18, 2017).

5. http://www.vice.com/motherboard/the-space-composer (last accessed on February 20, 2015).

6. Many sonifications are made for monitory purposes, but these usually assume a listener who is too busy with other tasks to actively interact with the sound. If monitory interactive listening is appropriate for car drivers but not usually for sonification users, this is because the sound of a car engine is a by-product, whereas the sound of the sonification is designed as a goal on its own account; a change in the sound of the sonification would usually be explicitly and deliberately caused by the user, whereas a change in the sound of an engine might be a side effect.

\section{REFERENCES}

Adorno, T. W. (1977/1962). Typen musikalischen Verhaltens. In Einleitung in die Musiksoziologie (pp. 14-34). Frankfurt am Main: Suhrkamp Verlag.

Bijsterveld, K., \& Krebs, S. (2013). Listening to the Sounding Objects of the Past: The Case of the Car. In K. Franinović \& S. Serafin (Eds.), Sonic Interaction Design (pp. 3-38). Cambridge: MIT Press.

Bijsterveld, K., Cleophas, E., Krebs, S., \& Mom, G. (2014). Sound and Safe: A History of Listening Behind the Wheel. Oxford: Oxford University Press.

Bregman, A. (1994). Auditory Scene Analysis: The Perceptual Organization of Sound. Cambridge: MIT Press.

Bruyninckx, J. (2013). Sound Science: Recording and Listening in the Biology of Bird Song, 1880-1980 (Ph.D. thesis, Maastricht University).

Chion, M. (2005/1990). Audio-Vision: Sound on Screen. New York: Columbia University Press.

Dayé, C., \& de Campo, A. (2006). Sounds Sequential: Sonification in the Social Sciences. Interdisciplinary Science Reviews, 31(4), 349-364.

Dell'Antonio, A. (Ed.). (2004). Beyond Structural Listening? Postmodern Modes of Hearing. Berkeley: University of California Press.

Douglas, S. J. (1999). Listening In: Radio and the American Imagination, from Amos ' $n$ ' Andy and Edward R. Murrow to Wolfman Jack and Howard Stern. New York: Times Books. 
Flowers, J. (2005). Thirteen Years of Reflection on Auditory Graphing: Promises, Pitfalls, and Potential New Directions. In Proceedings of the 11th International Conference on Auditory, Display, Limerick, Ireland, July 6-9 (pp. 405-409).

Gaver, W. W. (1989). The SonicFinder: An Interface That Uses Auditory Icons. Human-Computer Interaction, 4(1), 67-94.

Gibling, S. P. (1917). Types of Musical Listening. Musical Quarterly, 3(3), 385-389.

Goodman, D. (2010). Distracted Listening: On Not Making Sound Choices in the 1930s. In D. Suisman \& S. Strasser (Eds.), Sound in the Age of Mechanical Reproduction (pp. 15-46). Philadelphia: University of Pennsylvania Press.

Grond, F., \& Hermann, T. (2014). Interactive Sonification for Data Exploration: How Listening Modes and Display Purposes Define Design Guidelines. Organised Sound, 19(1), 41-51.

Harris, A. (2015). Sounding Disease: Guest Blog at Sociology of Diagnosis website. Available at https://www.facebook.com/SociologyOfDiagnosis/ posts/799049830181091. Last accessed August 18, 2017.

Harris, A., \& Van Drie, M. (2015). Sharing Sound: Teaching, Learning and Researching Sonic Skills. Sound Studies: An Interdisciplinary Journal, l(1), 98-117.

Hermann, T. (2002). Sonification for Exploratory Data Analysis (Ph.D. thesis, Bielefeld University).

Hermann, T. (2011). Model-Based Sonification. In T. Hermann, A. Hunt, \& J. G. Neuhoff (Eds.), The Sonification Handbook (pp. 399-427). Berlin: Logos Verlag.

Hermann, T., \& Hunt, A. (2005). An Introduction to Interactive Sonification. IEEE Multimedia, 12(2), 20-24.

Hermann, T., \& Hunt, A. (2011). Interactive Sonification. In T. Hermann, A. Hunt, \& J. G. Neuhoff (Eds.), The Sonification Handbook (pp. 273-298). Berlin: Logos Verlag.

Hermann, T., Hunt, A., \& Neuhoff, J. G. (2011). Introduction. In The Sonification Handbook (pp. 1-6). Berlin: Logos Verlag.

Hui, A. (2013). The Psychophysical Ear: Musical Experiments, Experimental Sounds, 1840-1910. Cambridge: MIT Press.

Krebs, S. (2012a). Automobilgeräusche als Information: Über das geschulte Ohr des Kfz-Mechanikers. In A. Schoon \& A. Volmar (Eds.), Das geschulte Ohr: Eine Kulturgeschichte der Sonifikation (pp. 95-110). Bielefeld: Transcript.

Krebs, S. (2012b). "Notschrei eines Automobilisten" oder die Herausbildung des Kfz-Handwerks in Deutschland. Technikgeschichte, 79(3), 185-206.

Krebs, S. (2012c). "Sobbing, Whining, Rumbling": Listening to Automobiles as Social Practice. In T. Pinch \& K. Bijsterveld (Eds.), The Oxford Handbook of Sound Studies (pp. 79-101). Oxford: Oxford University Press. 
Krebs, S. \& Van Drie, M. (2014). The Art of Stethoscope Use: Diagnostic Listening Practices of Medical Physicians and "Auto Doctors", ICON: Journal of the International Committee for the History of Technology, 20(2), 92-114.

Lacey, Kate. (2013). Listening Publics: The Politics and Experience of Listening in the Media Age. Cambridge: Polity Press.

Landi, E., Alexander, R. L., Gruesbeck, J. R., Gilbert, J. A., Lepri, S. T., Manchester, W. B., et al. (2012). Carbon Ionization Stages as a Diagnostic of the Solar Wind. The Astrophysical Journal, 744(2), 100.

Lorimer, J. (2008). Counting Corncrakes: The Affective Science of the UK Corncrake Census. Social Studies of Science, 38(3), 377-405.

Maisonneuve, S. (2001). Between History and Commodity: The Production of a Musical Patrimony Through the Record in the 1920-1930s. Poetics, 29(2), 89-108.

Mody, C. C. M. (2005). The Sounds of Science: Listening to Laboratory Practice. Science, Technology and Human Values, 30(2), 175-198.

Pinch, T., \& Bijsterveld, K. (2012). New Keys to the World of Sound. In The Oxford Handbook of Sound Studies (pp. 3-35). Oxford: Oxford University Press.

Rice, T. (2008). "Beautiful Murmurs": Stethoscopic Listening and Acoustic Objectification. Senses and Society, 3(3), 293-306.

Rice, T. (2010). "The Hallmark of a Doctor": The Stethoscope and the Making of Medical Identity. Journal of Material Culture, 15(3), 287-301.

Roosth, S. (2009). Screaming Yeast: Sonocytology, Cytoplasmic Milieus, and Cellular Subjectivities. Critical Inquiry, 35(2), 332-350.

Slabbekoorn, H., \& Peet, M. (2003). Ecology: Birds Sing at a Higher Pitch in Urban Noise. Nature, 424(6946), 267.

Stockfelt, O. (1997). Adequate Modes of Listening. In D. Schwarz, A. Kassabian, \& L. Siegel (Eds.), Keeping Score: Music, Disciplinarity, Culture (pp. 129-146). Charlottesville: University Press of Virginia.

Subotnik, R. R. (1991). Developing Variations: Style and Ideology in Western Music. Minneapolis: University of Minnesota Press.

Subotnik, R. R. (1996). Toward a Deconstruction of Structural Listening: A Critique of Schoenberg, Adorno, and Stravinsky. Deconstructive Variations: Music and Reason in Western Society (pp. 148-176). Minneapolis: University of Minnesota Press.

Summers, E. (1916). Notation of Bird Songs and Notes. The Auk, 33(1), 78-80.

Supper, A. (2012). Lobbying for the Ear: The Public Fascination with and Academic Legitimacy of the Sonification of Scientific Data (Ph.D. thesis, Maastricht University).

Supper, A. (2015). Sound Information: Sonification in the Age of Complex Data and Digital Audio. Information \& Culture: A Journal of History, 50(4), 441-464. 
Supper, A., \& Bijsterveld, K. (2015). Sounds Convincing: Modes of Listening and Sonic Skills in Knowledge Making. Interdisciplinary Science Reviews, $40(2), 124-144$.

Thorpe, W. H. (1958). The Learning of Song Patterns by Birds, with Especial Reference to the Songs of the Chaffinch 'Fringilla Coelebs'. The Ibis, 100(4), $535-570$.

Truax, B. (2001/1984). Acoustic Communication (2nd ed.). Westport: Greenwood.

Van Drie, M. (2013). Training the Auscultative Ear: Medical Textbooks and Teaching Tapes (1950-2010). The Senses and Society, 8(2), 165-191.

Vickers, P. (2011). Sonification for Process Monitoring. In T. Hermann, A. Hunt, \& J. G. Neuhoff (Eds.), The Sonification Handbook (pp. 455-491). Berlin: Logos Verlag.

Vickers, P. (2012). Ways of Listening and Modes of Being: Electroacoustic Auditory Display. Journal of Sonic Studies, 2(1). Available at http://journal. sonicstudies.org/vol02/nr01/a04. Last accessed August 18, 2017.

Walker, B. N., \& Nees, M. A. (2011). Theory of Sonification. In T. Hermann, A. Hunt, \& J. G. Neuhoff (Eds.), The Sonification Handbook (pp. 9-39). Berlin: Logos Verlag.

Williams, S. M. (1994). Perceptual Principles in Sound Grouping. In G. Kramer (Ed.), Auditory Display: Sonification, Audification, and Auditory Interfaces (pp. 95-125). Reading: Addison-Wesley Publishing Company.

Worrall, D. (2009). Sonification and Information: Concepts, Instruments and Techniques (Ph.D. thesis, University of Canberra).

Zwikker, C. (1934). De oorzaken van het geluid bij automobielen. In Anonymous, Verslag van het 'Anti-lawaai Congres,' georganiseerd te Delft, op 8 november 1934 door de Koninklijke Nederlandsche Automobile Club in samenwerking met de Geluidstichting (pp. 70-77). Delft: KNAC/Geluidstichting. 
Open Access This chapter is licensed under the terms of the Creative Commons Attribution-NonCommercial 4.0 International License (http:// creativecommons.org/licenses/by-nc/4.0/), which permits any noncommercial use, sharing, adaptation, distribution and reproduction in any medium or format, as long as you give appropriate credit to the original author(s) and the source, provide a link to the Creative Commons license and indicate if changes were made.

The images or other third party material in this chapter are included in the chapter's Creative Commons license, unless indicated otherwise in a credit line to the material. If material is not included in the chapter's Creative Commons license and your intended use is not permitted by statutory regulation or exceeds the permitted use, you will need to obtain permission directly from the copyright holder.

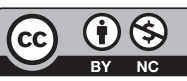

